Table 1

\begin{tabular}{ccccc}
\hline Subject & on/ot & \multicolumn{1}{c}{$\mathrm{d}^{\prime}$} & Chi Square & df \\
\hline 1 & 1.08 & 2.00 & 9.38 & 3 \\
2 & 1.14 & 1.57 & 2.32 & 3 \\
3 & 0.94 & -0.02 & 2.55 & 2 \\
4 & 0.89 & 1.33 & 2.16 & 3 \\
5 & 1.05 & 2.34 & $16.38^{*}$ & 3 \\
6 & 1.12 & 1.10 & 4.01 & 3 \\
7 & 1.04 & 1.61 & $20.55^{*}$ & 3 \\
8 & 0.93 & 0.12 & 0.40 & 2 \\
\hline
\end{tabular}

$\bullet p<.05$

probability of the taboo word divided by the probability of the neutral word should increase with the degree of confidence that the word was the taboo word. To determine if the data agreed with this hypothesis, a Spearman rank-order correlation was computed on each $S$ between the above probability ratio and the degree of confidence that the taboo word was presented. In five of the eight $S s$, the correlation was unity $(p<.01)$, and for the other three Ss, the correlation was positive, but not significant $(+.10,+.50$, and +.66$)$.

Also of interest is that fact that the sigma ratio (the ratio of the neutral-word standard deviation to the taboo-word standard deviation) averaged 1.02 over the eight Ss. Using the simultaneous $95 \%$ confidence intervals for the sigma ratio, based upon the variance estimates taken from the variance-covariance matrix, it was found that, for five of the eight Os, the sigma ratio was not significantly different from 1 , whereas for two of the Os, the sigma ratio was significantly greater than 1 , and for one of the Os, the sigma ratio was significantly less than 1. These results suggest that the assumption of a sigma ratio of about 1 is a reasonable assumption for these stimuli, at least on the average. For any particular $S$, the sigma ratio may or may not be 1 .

In summary, these data are in reasonably good agreement with signal-detection theory, and suggest that this theory can be applied to answer substantive questions about the recognition of such emotional stimuli as taboo words.

\section{REFERENCES}

DORFMAN, D. D. Recognition of taboo words as a function of a priori probability. Journal of Personality \& Social Psychology, 1967, 7, 1-10.

DORFMAN, D. D., \& ALF, E. F., JR. Maximum likelihood estimation of parameters of signal detection theory-a direct solution. Psychometrika, 1968, 33, 117-124.

DORFMAN, D. D., \& ALF, E. F., JR. Maximum likelihood estimation of parameters of signal detection theory-rating method data. Joumal of Mathematical Psychology, in press.

DORFMAN, D. D., GROSSBERG, J., \& KROEKER, $L$. Recognition of taboo stimuli as a function of exposure time. Journal of Personality 2 Social Psychology, 1965, 2 , 552-562.
SWETS, J. A., TANNER, W. P., JR., \& BIRDSALL, T. G. The evidence for a decision-making theory of visual detection. University of Michigan, Electronic Defense Group Technical Report No. 40, 1955.
NOTE

1. This research was supported in part by NSF-GS-1466. These data are part of a Master's thesis by the senior author. Dr. Donald D. Dorfman is now at the University of Iowa.

\title{
Meaningfulness $(\bar{m})$ : Its relation to frequency and specificity for children aged nine years
}

\author{
NORMA I. MICKELSON, University of \\ Victoria, Victoria, B.C., Canada
}

In this study, Mickelson's (1969) Table of Meaningfulness $(\bar{m})$ for 9 -year-old children was examined to determine whether or not meaningfulness $(\bar{m})$ is a function of frequency and specificity. The data indicate that for 9-year-old children, meaningfulness appears to be a function of specificity $\left(\chi^{2}\right.$, $3 d f, 11.47, p<.01 \%$. On the other hand, meaningfulness $(\bar{m})$ does not appear to be a function of frequency $\left(x^{2}, 3 d f, 5.6\right.$. $p>$.05).

The lack of normative data in the area of children's verbal learning up to the present has prohibited a valid examination of the function of variables that have been shown to facilitate adult verbal learning.

Mickelson (1969) developed a Table of Meaningulness $(\overline{\mathrm{m}})$ for 120 mass and count nouns. Ss were 135 children, aged 9 years, attending school in Saanich, a district adjacent to Victoria, B.C., Canada.

The words for the Table of Meaningfulness were randomly selected from the Thorndike-Lorge list (1944). The sample of words was stratified to control for frequency and specificity. Sixty A words and $60 \mathrm{AA}$ words were included (frequency). In each category, 30 mass and 30 count nouns (specificity) were randomly selected and included. The data revealed that the range of meaningfulness $(\bar{m})$ in the table for 9-year-old children was 8.41-.41, with a median of 4.25 and a mean of 4.29 .

The Table of Meaningfulness was then divided into quartiles. On the basis of probability, if meaningfulness is not a function of the variables specificity and frequency, it would be expected inat each quartile would contain an equal distribution of mass and count nouns and of $A$ and $A A$ nouns (Edwards, 1962, p. 63).

Two chi-square analyses of the data were carried out, the first to examine the observed and theoretical frequencies of nouns categorized according to specificity and the second to examine the observed and theore tical frequencies of nouns categorized according to frequency.

\section{RESULTS AND DISCUSSION}

The data in this study indicate that those words for which specificity can be defined (count nouns) appeared more often in the high meaningfulness quartiles of the Table of Meaningfulness than would be expected on the basis of probability $\left(\chi^{2}, 3 \mathrm{df}, 11.47 ; p<.01\right)$. For children aged 9 years, therefore, it would appear that high-meaningfulness words are more likely to be specific (count) nouns than nonspecific (mass) nouns. On the other hand, the data indicate that the variable meaningfulness $(\overline{\mathrm{m}})$ is not a function of frequency $\left(\chi^{2}, 3 \mathrm{df}, 5.6 ; \mathrm{p}>.05\right)$. One reason for this lack of relationship between high-meaningfulness nouns and frequency, as defined by Thorndike \& Lorge (1955), might well be that the Thorndike-Lorge frequency count is not relevant to the language used by today's children.

\section{REFERENCES}

EDWARDS, A. L. Experimental design in psychological research. (rev. ed.) New York: Holt, Rinehart \& Winston, 1962.

MICKELSON, N. I. Meaningfulness $(\bar{m})$ indices for 120 mass and count nouns for children aged nine years. Journal of Verbal Learning \& Verbal Behavior, 1969, 8, 80-82.

THORNDIKE, E. L., \& LORGE, l. The teacher's word book of 30,000 words. New York: Bureau of Publications, Teachers College, Columbia University, 1944. 